\title{
Decreased comorbidities in rheumatoid arthritis patients treated with a biologic agent
}

\author{
Yu-Jih $\mathrm{Su}^{1}$ and Ho-Chang Kuo ${ }^{1}$ \\ ${ }^{1}$ Chang Gung Memorial Hospital Kaohsiung Branch
}

September 24, 2020

\begin{abstract}
Objective. Biologics have been linked to both anti-autoimmune and anti-inflammatory mechanisms. We examine the long-term effects of biologics on rheumatoid arthritis (RA) patients in a real-world analytic cohort study using a nationwide database. Design. We designed a cohort study using the National Health Insurance Research Database in Taiwan between 1997 and 2010. Methods. Based on biologics and other anti-rheumatic agent prescriptions, we divided all patients into either the biologics group or the non-biologics group. The outcomes were the incidence rate of each comorbidity and the hazard ratio of each comorbidity between those using biologics and those not. We followed patients from the index date to the date on which the database ended. Results. In total, 19,681 patients were eligible for analysis in this study. During an average follow-up of 15 years, the event rates of each comorbidity differed significantly between the users and non-users of biologics with regard to cardiovascular comorbidity, metabolic comorbidity, rheumatologic comorbidity, and the miscellaneous comorbidity (all $\mathrm{p}<0.05$ ). The usage of biologic agents in RA patients reduced the HR of cardiovascular comorbidities by $18 \%$, metabolic comorbidities by $17 \%$, rheumatology comorbidities by $36 \%$, and miscellaneous comorbidities by $15 \%$ compared to those patients who did not use biologics. Oncology comorbidities and infection comorbidities were not affected by treatment with biologics ( $\mathrm{p}>0.05)$. Conclusions. Biologics may have benefits beyond arthritis control with regard to reducing real-world comorbidities.
\end{abstract}

\section{Objective.}

Biologics have been linked to both anti-autoimmune and anti-inflammatory mechanisms. We examine the long-term effects of biologics on rheumatoid arthritis (RA) patients in a real-world analytic cohort study using a nationwide database.

\section{Design.}

We designed a cohort study using the National Health Insurance Research Database in Taiwan between 1997 and 2010 .

\section{Methods.}

Based on biologics and other anti-rheumatic agent prescriptions, we divided all patients into either the biologics group or the non-biologics group. The outcomes were the incidence rate of each comorbidity and the hazard ratio of each comorbidity between those using biologics and those not. We followed patients from the index date to the date on which the database ended.

\section{Results.}

In total, 19,681 patients were eligible for analysis in this study. During an average follow-up of 15 years, the event rates of each comorbidity differed significantly between the users and non-users of biologics with regard to cardiovascular comorbidity, metabolic comorbidity, rheumatologic comorbidity, and the miscellaneous comorbidity (all $\mathrm{p}<0.05$ ). The usage of biologic agents in RA patients reduced the HR of cardiovascular 
comorbidities by $18 \%$, metabolic comorbidities by $17 \%$, rheumatology comorbidities by $36 \%$, and miscellaneous comorbidities by $15 \%$ compared to those patients who did not use biologics. Oncology comorbidities and infection comorbidities were not affected by treatment with biologics $(\mathrm{p}>0.05)$.

\section{Conclusions.}

Biologics may have benefits beyond arthritis control with regard to reducing real-world comorbidities.

Keywords: rheumatoid arthritis, biologics, comorbidity, real-world data.

\section{Introduction}

In this study, we aimed to identify whether biologics treatment in rheumatoid arthritis (RA) patients was capable of preventing comorbidities in this population [1]. Biologics have been used for more than 15 years in Taiwan, and their efficacy has been discussed elsewhere and confirmed to be protective against joint structure damage in RA patients. Whether biologics' beneficial effect influences comorbidities throughout the body is still under evaluation.

Among RA patients, the first comorbidities that need to be considered are cardiovascular events, followed by metabolic problems like diabetes and dyslipidemia. Diabetes mellitus, together with a number of risk factors of metabolic origin, can result in an increased risk for early mortality [2]. Considerable evidence has demonstrated that chronic low-grade inflammation caused by activating the innate immune system is vital in the pathogenesis of diabetes and other major complications. Diabetes is also a risk factor for cardiovascular comorbidities itself. In addition to these common comorbidities, RA is an autoimmune disease that can overlap other rheumatic or orthopedic-related comorbidities, such as gout, osteoporotic fractures, inflammatory bowel disease, psoriasis, etc. In the long run, the malignancy could be devastating due to chronic inflammation and tissue damage in RA patients.

Several other comorbidities that need to be considered include infectious diseases caused by the immune deviation of RA patients or the hepatic or nephrotic damage caused by medication side effects. Such pulmonary diseases as interstitial lung disease, asthmatic bronchitis, or chronic obstructive pulmonary disease are all listed in our analysis (Table 1).

The purpose of this study was to determine the long-term effect of biologic agents on RA patients in a real-world setting by using a nationwide database. Therefore, we designed a simulated analytic cohort study with strict selection and matching to determine whether long-term biologic agent use could affect the overall mortality rate of RA patients. In the current retrospective study, we compared the mortality rate between biologics users and non-biologics users in RA patients in Taiwan.

\section{Materials and Methods}

The single-payer compulsory National Health Insurance (NHI) program was initiated in Taiwan in 1995. The program provides universal coverage to most residents in Taiwan. The NHI Research Database (NHIRD) provided data about complete outpatient visits, hospital admissions, prescriptions, catastrophic illness information, and vital status of $99 \%$ of Taiwan's 23 million people. The bureau of the NHI released the NHIRD for research purposes. In this study, we adopted the data obtained through the Longitudinal Health Insurance Database 2005 (LHID 2005) from the NHIRD. This LHID 2005 database included registration and medical claims for 1,000,000 randomly sampled patients from the total number of NHRI enrollees. The LHID2005 data set allows researchers to follow up on all the medical services utilized by these 1,000,000 individuals since the initiation of the NHI in 1995. To protect individual privacy, the original identification numbers of the beneficiaries' data were encrypted for privacy. Encryption procedures were consistent with other datasets and ensured that all claims data could be linked in order to obtain additional medically relevant data. All data that could be used to identify patients or care providers, including the names of medical institutions and physicians, were encrypted. Our study protocol was approved by the institute review board of Chang Gung Memorial Hospital, Kaohsiung, Taiwan without the need of any informed consent.

Data source 
We derived the real-world data of this prospective cohort study from Taiwan's National Health Insurance Research Database (NHIRD). NHIRD is an administrative database from Taiwan's National Health Insurance (NHI) program, the country's compulsory and single-payer national health insurance system. The NHI program covers almost all outpatient visits, emergency room services, admission services, medical care services, and medications. Services include physician diagnosis, blood tests like biochemistry and complete blood count, imaging studies like chest X-rays and computed tomography, medication, and surgery. The bureau of the NHI released the NHIRD for research purposes. In this study, we adopted the data obtained through the Longitudinal Health Insurance Database 2005 (LHID 2005) from the NHIRD. This LHID 2005 database included registration and medical claims for 1,000,000 randomly sampled patients from the total number of NHRI enrollees. The LHID2005 data set allows researchers to follow up on all the medical services utilized by these 1,000,000 individuals since the start of the NHI in 1995.

This study was approval by the Chang Gung Medical Foundation's Institutional Review Board (IRB No.: 201600763B1).

\section{Study design}

To protect individual privacy, the original identification numbers of the beneficiaries' data were encrypted for privacy. Encryption procedures were consistent with other datasets and ensured that all claims data could be linked in order to obtain additional medically relevant data. All data that could be used to identify patients or care providers, including the names of medical institutions and physicians, were encrypted. Patients with RA (the international classification of diseases, ninth revision (ICD-9) with 714.0) in the LHID 2005 were initially screened. We confirmed RA diagnosis using catastrophic illness certification (CIC) according to the NHI program regulations $[3,4]$. Therefore, all RA diagnoses required the agreement of two rheumatologists, one application rheumatologist and one anonymous senior rheumatologist as the reviewer. All rheumatologists met the following two criteria: three-year internal medicine residents training in a quality hospital, usually a tertiary hospital, and two-year rheumatology fellow training. "Senior" usually refers to a rheumatologist career that has spanned at least 10 years.

Co-morbidities and outcomes

Since the LHID 2005 does not include laboratory exam result $\backslash$ souts (i.e., HbA1C, c-reactive protein), we selected several clinical indicators to represent disease comorbidities, including several major organ diseases such as cardiovascular comorbidities, endocrine comorbidities, rheumatic or orthopedics comorbidities, oncology comorbidities, infection comorbidities, and miscellaneous comorbidities. Such comorbidities as hypertension, dyslipidemia, gout, chronic kidney disease, coronary artery disease, interstitial lung disease, malignancy, stroke, and hepatitis B/C were recorded.

\section{Statistical analysis}

We carried out chi-square analysis in order to compare the biologics and non-biologics groups. We compared the characteristics of the biologics patients and non-biologics patients, adopting the t-test for continuous variables and the chi-square test for categorical variables. The incidence of mortality was reported as the event rate (proportion of events) and incidence density (number of events per 100 person-years). We adopted Cox proportional hazard model to compare the risk of mortality between the two groups. Furthermore, we used the Poisson regression model to compare the annual number of admissions for autoimmune disease between the study groups, treating the log-transformed follow-up year as an offset variable. Finally, the hazard ratio of the patients of the two groups was calculated with survival analysis. We considered a $p$ -value $<0.05$ to be statistically significant. All data analysis was conducted using SAS software version 9.4 (SAS Institute, Cary, NC).

- $\quad$ Ethics approval and consent to participate

This retrospective database analysis study involving human participants was in accordance with the ethical standards of the institutional and national research committee and with the 1964 Helsinki Declaration and 
its later amendments or comparable ethical standards. The Longitudinal Health Insurance Database 2005 provides only de-identified samples, which Ethical approval was waived by the local Ethics Committee.

\section{Results}

Eligible patients

We found a total of 19,681 patients with RA in the Longitudinal Health Insurance Database 2005 (LHID 2005). Of those, 15,097 patients had cardiovascular diagnostic coding. Patients who did not have associated cardiovascular coding were not listed in Table 2 for analysis. Among these patients, 4,810 patients were diagnosed with RA, nine of which were treated with biologic agents. Similarly, 13,384 patients had metabolic diagnostic coding. Patients that did not have associated metabolic coding were not listed in Table 2 for analysis. Among these patients, 5,680 patients were diagnosed with RA, nine of which were treated with biologic agents.

In the LHID 2005 database, 18,114 patients had rheumatologic or orthopedic diagnostic coding. Patients who did not have associated rheumatologic or orthopedic coding were not listed in Table 2 for analysis. Among these patients, 2,269 patients were diagnosed with RA, seven of which were treated with biologic agents. Again, in the LHID 2005 database, 19,681 patients had oncologic diagnostic coding. Patients that did not have associated oncologic coding were not listed in Table 2 for analysis. Among these patients, 3,148 patients were diagnosed with RA, 23 of which were treated with biologic agents. Of the 18,944 patients with infectious related diagnostic coding, 1,092 patients were diagnosed with RA, and seven of those were treated with biologic agents. Finally, 13,047 had miscellaneous diagnostic coding related to RA. Among these patients, 4,996 patients were diagnosed with RA, seven of which were treated with biologic agents.

Baseline characteristics for study participants

Table 2 lists patient characteristics with rheumatoid arthritis, their comorbidities, and their treatment status with or without biologic agents. We found a total of 19,681 patients with RA in the Longitudinal Health Insurance Database 2005 (LHID 2005). Of those, 19,323 patients were older than sixteen years old, while the remaining 358 patients were sixteen years old or younger. In total, the sample included 12,720 female patients and 6,961 male patients. Basically, the biologics users accounted for only a few patients compared to non-biologics users. Only 156 patients among the LHID 2005 cohort used biologics. We observed no statistical significance regarding using biologics between those older and younger than sixteen years old $(\mathrm{p}=0.61)$. On the other hand, we observed significant differences between male and female patients using biologics $(\mathrm{p}<0.0001)$.

Biologics are beneficial regarding cardiovascular comorbidity, metabolic comorbidity, rheumatologic comorbidity, and miscellaneous comorbidity in the current study

With an average 15-year follow-up duration, the event rate of different medical comorbidities in the biologics group and in the non-biologics group are shown in Table 2, which compares the incidence of each comorbidity with the usage of biologic agents. This result indicates that the incidence rates of cardiovascular comorbidity, metabolic comorbidity, rheumatologic comorbidity, and miscellaneous comorbidity were all significantly lower in the biologics group (all $\mathrm{p}<0.05$ ). However, the usage of biologic agents does not change the incidence of oncology or infectious comorbidities (both $\mathrm{p}>0.05$, Table 2 ).

Outcomes of multivariate-adjusted hazard ratio (HR) of each comorbidity

Both the detailed incidence rate and the hazard ratio (HR) of each comorbidity in RA patients are demonstrated in Table 3. The effects of gender, age, and biologics to each comorbidity were demonstrated separately. The occurrence of cardiovascular comorbidities was $9 \%$ higher in male RA patients than in female RA patients (crude HR), or 10\% higher with multivariate-adjusted HR. The occurrence of cardiovascular comorbidities was 27.63 times higher in RA patients over the age of 16 years than in RA patients 16 years old and younger (crude HR), or 28.11 times higher with multivariate-adjusted HR. The use of biologic agents in RA 
patients could reduce both the crude HR and the multivariate-adjusted HR of cardiovascular comorbidities by $18 \%$ compared to those patients who did not (Table 3 ).

The metabolic comorbidities occur $11 \%$ more in female RA patients than in male RA patients (crude HR), or $10 \%$ more with multivariate-adjusted HR in female RA patients. Metabolic comorbidities are 5.79 times more likely in RA patients over the age of 16 years old than in RA patients 16 years old or younger (crude HR), or 5.72 times higher with multivariate-adjusted HR. The use of biologic agents in RA patients could reduce both the crude HR and the multivariate-adjusted HR of metabolic comorbidities by $17 \%$ compared to those patients who did not (Table 3 ).

Rheumatology comorbidities were $3 \%$ higher in female RA patients than in male RA patients (crude HR), or $3 \%$ higher with multivariate-adjusted HR. They were 1.25 times higher in RA patients over the age of 16 years old than in RA patients 16 years old or younger (crude HR), or 1.25 times higher with multivariateadjusted HR. The usage of biologic agents in RA patients could reduce the HR of rheumatology comorbidities by $36 \%$ compared to those patients who did not with crude HR and by $35 \%$ compared to those patients who did not with the multivariate-adjusted HR. (Table 3).

Oncology comorbidities occurred $25 \%$ more in male RA patients than in female RA patients (crude HR), or $26 \%$ more with multivariate-adjusted HR. Regarding age, the oncology comorbidities were 3.37 times higher in RA patients over the age of 16 years old than in RA patients 16 years old or younger (crude HR), or 3.5 times higher with multivariate-adjusted HR. The use of biologic agents in RA patients could reduce both the crude HR and the multivariate-adjusted HR of oncology comorbidities by $65 \%$ compared to those patients who did not, but we observed no significant statistical differences between users and non-users of biologics (p>0.05) (Tables 2 and 3).

Infection comorbidities were $25 \%$ more likely in male RA patients than in female RA patients (crude HR), or $26 \%$ more likely with multivariate-adjusted HR. The occurrence of infection comorbidities was 3.37 times higher in RA patients over the age of 16 years old than in RA patients 16 years old or younger (crude HR), or 3.5 times higher with multivariate-adjusted HR. The usage of biologic agents in RA patients could reduce the HR of infection comorbidities by $77 \%$ compared to those patients who did not with crude HR and by $81 \%$ of those patients who did not with the multivariate-adjusted HR. However, no statistically significant differences were found between users and non-users of biologics ( $\mathrm{p}>0.05)$ (Tables 2 and 3).

Miscellaneous comorbidities were $6 \%$ higher in male RA patients than in female RA patients (crude HR), or 7\% higher with multivariate-adjusted HR. The miscellaneous comorbidities were 1.52 times higher in RA patients over the age of 16 years old than in RA patients 16 years old or younger (crude HR), or 1.55 times higher with multivariate-adjusted HR. The usage of biologic agents in RA patients could reduce both the crude HR and the multivariate-adjusted HR of miscellaneous comorbidities to $15 \%$ of those patients who did not (Table 3).

\section{Discussion}

This large RA cohort study demonstrates that patients that have been prescribed biologics have a significantly decreased rate of cardiovascular comorbidity, metabolic comorbidity, rheumatologic comorbidity, and miscellaneous comorbidity (all $\mathrm{p}<0.05$ ), but with a similar rate of oncology and infectious comorbidity incidence (both $\mathrm{p}>0.05$ ) (Table 2). The extra-joint benefitfrom being treated with the biologics has been documented by previous studies, including improved cardiovascular outcome [5], improved insulin resistance [6], improved trabecular bone mass, and decreased bone loss [7, 8], but with a stable malignancy rate [9]. Furthermore, a recent article mentioned that patients with RA appeared to be at a higher risk of lung cancer and lymphoma, but a lower risk of colorectal and breast cancer [10], which contribute equally to the malignancy rate. Also, that the biologic agents did not induce malignancy was demonstrated in another meta-analysis research [11]. On the other hand, the infection comorbidities, which should be increased in patients treated with biologics $[12,13]$, was not seen in our current study. This finding may have been because the risk management program arose before all the biologic agents could be issued by physicians, thus making the incidence rate of infections too low to be detected in this cohort. 
The prescription of biologic agents to RA patients was not affected byage discrimination ( $\mathrm{p}=0.61)$, but it was affected bygender, with female being predominant $(\mathrm{p}<0.0001)$ (Table 2$)$. One possible explanation for this phenomenon is that the female RA patients may have higher pain scores [14], which could be a surrogate marker for higher disease activity, implying a much higher chance to get access to biologics treatment. Regarding the age effect of comorbidities (Table 3), a selection bias may arise in treating juvenile RA or adult RA patients $[15,16]$, but age itself is still a risk factor for all the comorbidities in treating RA patients [17].

In the current study, the infection outcome comparison between biologics users and non-biologics users seems to be neutral, which differs from previous studies on the deteriorated effect of biologics with regard to tuberculosis infection [11], bacterial infection [18], and other opportunistic infections [19-21]. The different results of infection rate could be a bias related to a mixture of different mechanisms of biologics [22, 23] or different components of the biologics [23].

Regarding miscellaneous comorbidities, whether exposure to biologics has a deteriorating [24] or neutral [25] effect on kidney function is still debated, but biologics may have benefits related to reducing chronic obstructive pulmonary disease in RA patients [26]. Furthermore, other studies have been performed on biologics in cardiovascular events [5, 27], hepatoma [28], cancers [5], and atherothrombosis [29]. To the best of our knowledge, no specific research dealing with the biologics effect on miscellaneous comorbidities has yet been published.

Likewise, respiratory failure is mostly caused by inflammation [30] and increased oxidative stress [31]. Biologics may be significantly associated with lung disease in RA patients [32-34]. Another review article mentioned that MTX, LEF, TNFi, RTX, and TCZ may cause pneumonitis [35], which was not demonstrated in our current study and warrants further investigation.

Our study has certain limitations that should be mentioned at this point. This study is designed to evaluate an organ system-oriented comorbidity in RA, which limits the individual causative etiology of comorbidity results. Furthermore, this retrospective observation cohort study only reflects a particular interval of time, which certain types of biologic agents available in Taiwan. Different time inveral and a different mixture of patients could have different results. In general, we found that biologics may be associated with decreasing several comorbidities in RA patients in this particular cohort study.

- $\quad$ Table 1. Comorbidities of rheumatoid arthritis, categorized by system

Cardiovascular:

- Atrial fibrillation (ICD-9: 427.31)

- Hypertension (ICD-9: 401-405)

- Acute myocardial infarction: Any hospitalization with a diagnosis of ICD-9: 410.x

- Coronary heart disease (ICD-9: 410-414)

- Heart failure (ICD-9: 398.91, 402.01, 402.11, 402.91, 404.01, 404.03, 404.11, 404.13, 404.91, 404.93, or 428)

- Cerebral vascular incident (CVA) (ICD-9: 430-438)

- Deep vein thrombosis (DVT) and pulmonary thromboembolism (PE): PE (ICD-9: 415.1), iatrogenic PE (ICD-9: 415.11), and DVT (ICD-9: 453.8)

Endocrine:

- Hyperlipidemias (ICD-9: 272)

- Diabetes mellitus (ICD-9: 250)

- Thyroid disorders: thyroid cancer (ICD-9: 193), hypothyroidism (ICD-9: 244), hyperthyroidism (ICD9: 242), and thyroiditis (ICD-9: 245)

Rheumatic or orthopedics: 
- Gout (ICD-9: 274)

- Hip fracture (ICD-9: 820) and operation codes 7855, 7925, 7935, 7995, or 8152

- Inflammatory bowel disease: ulcerative colitis (ICD-9: 556) and Crohn's disease (ICD-9: 555)

- Psoriasis (ICD-9: 696, 696.1 or 696.8)

Oncology:

- Malignancy (ICD-9: 140-208)

- Lymphoma (ICD-9: 200, 201, 202, or 203)

Infection:

Tuberculosis (ICD-9: 010.x-018.x)

Viral hepatitis: HBV (ICD-9: 070.2, 0.70.3, or V02.61) and HCV (ICD-9: 070.41, 070.44, 070.51, 070.54, or V02.62)

Miscellaneous:

- Chronic obstructive pulmonary disease (ICD-9: 491, 492, or 496)

- Asthma (ICD-9: 493)

- Chronic kidney disease (ICD-9: 582, 583, 585, 586, or 588)

- Chronic liver diseases (ICD-9: 456.0-456.2, 571.2, 571.4-571.6, or 572)

- Table 2. Demographic data of patients with rheumatoid arthritis, their incidence rates of comorbidities, and their treatment status with or without biologic agents.

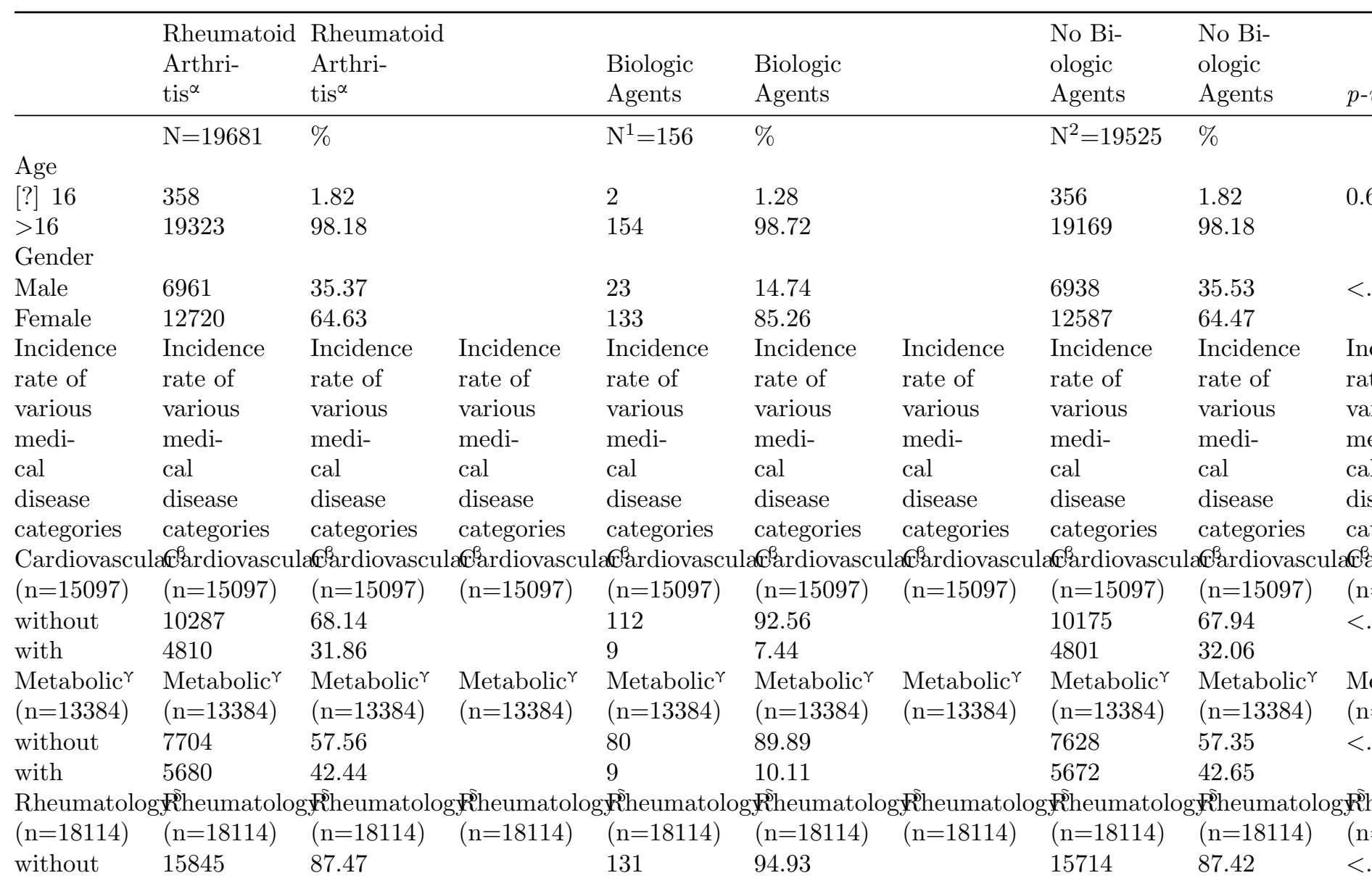




\begin{tabular}{|c|c|c|c|c|c|c|c|c|}
\hline & $\begin{array}{l}\text { Rheumatoid } \\
\text { Arthri- } \\
\text { tis }^{\alpha}\end{array}$ & $\begin{array}{l}\text { Rheumatoid } \\
\text { Arthri- } \\
\text { tis }^{\alpha}\end{array}$ & & $\begin{array}{l}\text { Biologic } \\
\text { Agents }\end{array}$ & $\begin{array}{l}\text { Biologic } \\
\text { Agents }\end{array}$ & & $\begin{array}{l}\text { No Bi- } \\
\text { ologic } \\
\text { Agents } \\
\end{array}$ & $\begin{array}{l}\text { No Bi- } \\
\text { ologic } \\
\text { Agents }\end{array}$ \\
\hline with & 2269 & 12.53 & & 7 & 5.07 & & 2262 & 12.58 \\
\hline $\begin{array}{l}\text { Oncology }^{\varepsilon} \\
(n=19681)\end{array}$ & $\begin{array}{l}\text { Oncology } \\
(\mathrm{n}=19681)\end{array}$ & $\begin{array}{l}\text { Oncology }^{\varepsilon} \\
(\mathrm{n}=19681)\end{array}$ & $\begin{array}{l}\text { Oncology }^{\varepsilon} \\
(\mathrm{n}=19681)\end{array}$ & $\begin{array}{l}\text { Oncology } \\
(\mathrm{n}=19681)\end{array}$ & $\begin{array}{l}\text { Oncology }^{\varepsilon} \\
(n=19681)\end{array}$ & $\begin{array}{l}\text { Oncology }^{\varepsilon} \\
(n=19681)\end{array}$ & $\begin{array}{l}\text { Oncology }^{\varepsilon} \\
(\mathrm{n}=19681)\end{array}$ & $\begin{array}{l}\text { Oncology }^{\varepsilon} \\
(\mathrm{n}=19681)\end{array}$ \\
\hline without & 16533 & 84.00 & & 133 & 85.26 & & 16400 & 83.99 \\
\hline with & 3148 & 16.00 & & 23 & 14.74 & & 3125 & 16.01 \\
\hline $\begin{array}{l}\text { Infection }^{\zeta} \\
(\mathrm{n}=18944)\end{array}$ & $\begin{array}{l}\text { Infection }^{\zeta} \\
(\mathrm{n}=18944)\end{array}$ & $\begin{array}{l}\text { Infection }^{\zeta} \\
(\mathrm{n}=18944)\end{array}$ & $\begin{array}{l}\text { Infection }^{\zeta} \\
(\mathrm{n}=18944)\end{array}$ & $\begin{array}{l}\text { Infection }^{\zeta} \\
(\mathrm{n}=18944)\end{array}$ & $\begin{array}{l}\text { Infection }^{\zeta} \\
(\mathrm{n}=18944)\end{array}$ & $\begin{array}{l}\text { Infection }^{\zeta} \\
(\mathrm{n}=18944)\end{array}$ & $\begin{array}{l}\text { Infection }^{\zeta} \\
(\mathrm{n}=18944)\end{array}$ & $\begin{array}{l}\text { Infection }^{\zeta} \\
(\mathrm{n}=18944)\end{array}$ \\
\hline without & 17852 & 94.24 & & 140 & 95.24 & & 17712 & 94.23 \\
\hline with & 1092 & 5.76 & & 7 & 4.76 & & 1085 & 5.77 \\
\hline $\begin{array}{l}\text { Miscellaneor } \\
(\mathrm{n}=13047)\end{array}$ & $\begin{array}{l}\text { asMiscellaneo } \\
(\mathrm{n}=13047)\end{array}$ & $\begin{array}{l}\text { sMiscellaneou } \\
(\mathrm{n}=13047)\end{array}$ & $\begin{array}{l}\text { asMiscellaneo } \\
(\mathrm{n}=13047)\end{array}$ & $\begin{array}{l}\text { isMiscellaneo } \\
(\mathrm{n}=13047)\end{array}$ & $\begin{array}{l}\text { asMiscellanec } \\
(\mathrm{n}=13047)\end{array}$ & $\begin{array}{l}\text { SMiscellanec } \\
(\mathrm{n}=13047)\end{array}$ & $\begin{array}{l}\text { usMiscellaneo } \\
(\mathrm{n}=13047)\end{array}$ & $\begin{array}{r}\text { asMiscellane } \\
(\mathrm{n}=13047)\end{array}$ \\
\hline without & 8051 & 61.71 & & 86 & 92.47 & & 7965 & 61.49 \\
\hline with & 4996 & 38.29 & & 7 & 7.53 & & 4989 & 38.51 \\
\hline
\end{tabular}

${ }^{\alpha}$ indicates ICD9: 714.0

juvenile inflammatory arthritis in patients 16 years old or younger, and those diagnosed as rheumatoid arthritis in patients over 16 years old.

$\beta$ indicates atrial fibrillation (ICD-9: 427.31), hypertension (ICD-9: 401-405), and acute myocardial infarction: Any hospitalization with a diagnosis of ICD-9: 410.x, coronary heart disease (ICD-9: 410-414), heart failure (ICD-9: 398.91, 402.01, 402.11, 402.91, 404.01, 404.03, 404.11, 404.13, 404.91, 404.93, or 428), cerebral vascular accident (CVA) (ICD-9: 430-438), deep vein thrombosis (DVT), and pulmonary thromboembolism (PE): PE (ICD-9: 415.1), iatrogenic PE (ICD-9: 415.11) and DVT (ICD-9: 453.8)

$\gamma$ indicates hyperlipidemias (ICD-9: 272), diabetes mellitus (ICD-9: 250), and thyroid disorders: thyroid cancer (ICD-9: 193), hypothyroidism (ICD-9: 244), hyperthyroidism (ICD-9: 242), and thyroiditis (ICD-9: 245)

${ }^{\circ}$ indicates gout (ICD-9: 274), hip fracture (ICD-9: 820), operation codes 7855, 7925, 7935, 7995, or 8152, and inflammatory bowel disease: ulcerative colitis (ICD-9: 556), Crohn's disease (ICD-9: 555), and psoriasis (ICD-9: 696, 696.1, and 696.8)

${ }^{\varepsilon}$ indicates malignancy (ICD-9: 140-208) and lymphoma (ICD-9: 200, 201, 202, or 203)

$\zeta$ indicates tuberculosis (ICD-9: 010.x-018.x) and viral hepatitis: HBV (ICD-9: 070.2, 0.70.3, and V02.61) and HCV (ICD-9: 070.41, 070.44, 070.51, 070.54, V02.62)

${ }^{n}$ indicates chronic obstructive pulmonary disease (ICD-9: 491, 492, and 496), asthma (ICD-9: 493), chronic kidney disease (ICD-9: 582, 583, 585, 586, and 588), and chronic liver diseases (ICD-9: 456.0-456.2, 571.2, $571.4-571.6$, and 572)

p-value demonstrates the chi-square analysis between each comorbidity and the usage of biologic agents.

* indicates $\mathrm{p}<0.05$

$\mathrm{N}^{1}$ indicates biologics users

$\mathrm{N}^{2}$ indicates non-biologics users

Table 3. Outcomes of crude and multivariate-adjusted hazard ratio (HR) of each comorbidity in rheumatoid arthritis patients. 


\begin{tabular}{|c|c|c|c|c|c|c|}
\hline & $\begin{array}{l}\text { Number of } \\
\text { patients }\end{array}$ & $\begin{array}{l}\text { Number of } \\
\text { person-years }\end{array}$ & $\begin{array}{l}\text { Number of } \\
\text { patients } \\
\text { with each } \\
\text { comorbidity }\end{array}$ & $\begin{array}{l}\text { Incident rate } \\
\text { (per 100,000 } \\
\text { person- } \\
\text { years) }\end{array}$ & $\begin{array}{l}\text { Crude HR } \\
(95 \% \mathrm{CI}) \\
\end{array}$ & $\begin{array}{l}\text { Multivariate- } \\
\text { adjusted } \\
\mathrm{HR}^{*}(95 \% \\
\mathrm{CI})\end{array}$ \\
\hline $\begin{array}{l}\text { Cardiovascular } \\
\text { comorbidities } \\
\text { Gender }\end{array}$ & $\begin{array}{l}\text { Cardiovascular } \\
\text { comorbidities }\end{array}$ & $\begin{array}{l}\text { Cardiovascular } \\
\text { comorbidities }\end{array}$ & $\begin{array}{l}\text { Cardiovascular } \\
\text { comorbidities }\end{array}$ & $\begin{array}{l}\text { Cardiovascular } \\
\text { comorbidities }\end{array}$ & $\begin{array}{l}\text { Cardiovascular } \\
\text { comorbidities }\end{array}$ & $\begin{array}{l}\text { Cardiovascular } \\
\text { comorbidities }\end{array}$ \\
\hline Female & 9874 & 67453.32 & 3044 & 4512.75 & 1.00 & 1.00 \\
\hline Male & 5223 & 35926.71 & 1766 & 4915.56 & $\begin{array}{l}1.09 \\
\left(1.03^{\sim} 1.16\right)\end{array}$ & $\begin{array}{l}1.10 \\
\left(1.04^{\sim} 1.17\right)\end{array}$ \\
\hline Age & & & & & & \\
\hline [?] 16 & 356 & 3055.91 & 5 & 163.62 & 1.00 & 1.00 \\
\hline$>16$ & 14741 & 100324.12 & 4805 & 4789.48 & $\begin{array}{l}28.63 \\
\left(11.91^{\sim} 68.01\right)\end{array}$ & $\begin{array}{l}29.11 \\
\left(12.11^{\sim} 69.98\right)\end{array}$ \\
\hline \multicolumn{7}{|l|}{$\begin{array}{l}\text { Biologic } \\
\text { agents }\end{array}$} \\
\hline No & 14976 & 102282.55 & 4801 & 4693.86 & 1.00 & 1.00 \\
\hline Yes & 121 & 1097.49 & 9 & 820.05 & $\begin{array}{l}0.18 \\
\left(0.09^{\sim} 0.35\right)\end{array}$ & $\begin{array}{l}0.18 \\
\left(0.09^{\sim} 0.35\right)\end{array}$ \\
\hline $\begin{array}{l}\text { Metabolic } \\
\text { comorbidities } \\
\text { Gender }\end{array}$ & $\begin{array}{l}\text { Metabolic } \\
\text { comorbidities }\end{array}$ & $\begin{array}{l}\text { Metabolic } \\
\text { comorbidities }\end{array}$ & $\begin{array}{l}\text { Metabolic } \\
\text { comorbidities }\end{array}$ & $\begin{array}{l}\text { Metabolic } \\
\text { comorbidities }\end{array}$ & $\begin{array}{l}\text { Metabolic } \\
\text { comorbidities }\end{array}$ & $\begin{array}{l}\text { Metabolic } \\
\text { comorbidities }\end{array}$ \\
\hline Female & 8405 & 53287.36 & 3663 & 43581.20 & 1.00 & 1.00 \\
\hline Male & 4979 & 33172.56 & 2017 & 40510.14 & $\begin{array}{l}0.89 \\
\left(0.85^{\sim} 0.94\right)\end{array}$ & $\begin{array}{l}0.90 \\
\left(0.85^{\sim} 0.95\right)\end{array}$ \\
\hline \multicolumn{7}{|l|}{ Age } \\
\hline [?] 16 & 350 & 2906.98 & 28 & 8000.00 & 1.00 & 1.00 \\
\hline$>16$ & 13034 & 83552.95 & 5652 & 43363.51 & $\begin{array}{l}6.79 \\
\left(4.69^{\sim} 9.84\right)\end{array}$ & $\begin{array}{l}6.72 \\
\left(4.64^{\sim} 9.75\right)\end{array}$ \\
\hline \multicolumn{7}{|l|}{$\begin{array}{l}\text { Biologic } \\
\text { agents }\end{array}$} \\
\hline No & 13295 & 85638.11 & 5671 & 42655.13 & 1.00 & 1.00 \\
\hline Yes & 89 & 821.82 & 9 & 10112.36 & $\begin{array}{l}0.17 \\
\left(0.09^{\sim} 0.33\right)\end{array}$ & $\begin{array}{l}0.17 \\
\left(0.09^{\sim} 0.32\right)\end{array}$ \\
\hline $\begin{array}{l}\text { Rheumatology } \\
\text { comorbidities } \\
\text { Gender }\end{array}$ & $\begin{array}{l}\text { Rheumatology } \\
\text { comorbidities }\end{array}$ & $\begin{array}{l}\text { Rheumatology } \\
\text { comorbidities }\end{array}$ & $\begin{array}{l}\text { Rheumatology } \\
\text { comorbidities }\end{array}$ & $\begin{array}{l}\text { Rheumatology } \\
\text { comorbidities }\end{array}$ & $\begin{array}{l}\text { Rheumatology } \\
\text { comorbidities }\end{array}$ & $\begin{array}{l}\text { Rheumatology } \\
\text { comorbidities }\end{array}$ \\
\hline Female & 11742 & 91810.66 & 1472 & 12536.19 & 1.00 & 1.00 \\
\hline Male & 6372 & 51469.19 & 797 & 12507.85 & $\begin{array}{l}0.97 \\
\left(0.89^{\sim} 1.06\right)\end{array}$ & $\begin{array}{l}0.97 \\
\left(0.89^{\sim} 1.06\right)\end{array}$ \\
\hline \multicolumn{7}{|l|}{ Age } \\
\hline [?] 16 & 339 & 2838.61 & 20 & 5899.71 & 1.00 & 1.00 \\
\hline$>16$ & 17775 & 140441.23 & 2249 & 12652.60 & $\begin{array}{l}2.25 \\
\left(1.45^{\sim} 3.50\right)\end{array}$ & $\begin{array}{l}2.25 \\
\left(1.45^{\sim} 3.49\right)\end{array}$ \\
\hline \multicolumn{7}{|l|}{$\begin{array}{l}\text { Biologic } \\
\text { agents }\end{array}$} \\
\hline No & 17976 & 142017.51 & 2262 & 12583.44 & 1.00 & 1.00 \\
\hline Yes & 138 & 1262.33 & 7 & 5072.46 & $\begin{array}{l}0.36 \\
\left(0.17^{\sim} 0.75\right)\end{array}$ & $\begin{array}{l}0.35 \\
\left(0.17^{\sim} 0.74\right)\end{array}$ \\
\hline $\begin{array}{l}\text { Oncology } \\
\text { comorbidities }\end{array}$ & $\begin{array}{l}\text { Oncology } \\
\text { comorbidities }\end{array}$ & $\begin{array}{l}\text { Oncology } \\
\text { comorbidities }\end{array}$ & $\begin{array}{l}\text { Oncology } \\
\text { comorbidities }\end{array}$ & $\begin{array}{l}\text { Oncology } \\
\text { comorbidities }\end{array}$ & $\begin{array}{l}\text { Oncology } \\
\text { comorbidities }\end{array}$ & $\begin{array}{l}\text { Oncology } \\
\text { comorbidities }\end{array}$ \\
\hline
\end{tabular}




\begin{tabular}{|c|c|c|c|c|c|c|}
\hline & $\begin{array}{l}\text { Number of } \\
\text { patients }\end{array}$ & $\begin{array}{l}\text { Number of } \\
\text { person-years }\end{array}$ & $\begin{array}{l}\text { Number of } \\
\text { patients } \\
\text { with each } \\
\text { comorbidity }\end{array}$ & $\begin{array}{l}\text { Incident rate } \\
\text { (per 100,000 } \\
\text { person- } \\
\text { years) } \\
\end{array}$ & $\begin{array}{l}\text { Crude HR } \\
(95 \% \mathrm{CI}) \\
\end{array}$ & $\begin{array}{l}\text { Multivariate- } \\
\text { adjusted } \\
\mathrm{HR}^{*}(95 \% \\
\mathrm{CI}) \\
\end{array}$ \\
\hline \multicolumn{7}{|l|}{ Gender } \\
\hline Female & 1974 & 106819.39 & 12720 & 644376.90 & 1.00 & 1.00 \\
\hline Male & 1174 & 60389.63 & 6961 & 592930.15 & $\begin{array}{l}1.04 \\
\left(0.97^{\sim} 1.12\right)\end{array}$ & $\begin{array}{l}1.04 \\
\left(0.97^{\sim} 1.12\right)\end{array}$ \\
\hline \multicolumn{7}{|l|}{ Age } \\
\hline $\begin{array}{l}{[?] 16} \\
>16\end{array}$ & $\begin{array}{l}10 \\
3138\end{array}$ & $\begin{array}{l}3121.68 \\
164087.34\end{array}$ & $\begin{array}{l}358 \\
19323\end{array}$ & $\begin{array}{l}3580000.00 \\
615774.38\end{array}$ & $\begin{array}{l}1.00 \\
6.23 \\
\left(3.35^{\sim} 11.58\right)\end{array}$ & $\begin{array}{l}1.00 \\
6.26 \\
\left(3.37^{\sim} 11.64\right)\end{array}$ \\
\hline \multicolumn{7}{|l|}{$\begin{array}{l}\text { Biologic } \\
\text { agents }\end{array}$} \\
\hline No & 3125 & 165753.94 & 19525 & 624800.00 & 1.00 & 1.00 \\
\hline Yes & 23 & 1455.08 & 156 & 678260.87 & $\begin{array}{l}0.65 \\
\left(0.43^{\sim} 0.98\right)\end{array}$ & $\begin{array}{l}0.65 \\
\left(0.43^{\sim} 0.98\right)\end{array}$ \\
\hline $\begin{array}{l}\text { Infection } \\
\text { comorbidities } \\
\text { Gender }\end{array}$ & $\begin{array}{l}\text { Infection } \\
\text { comorbidities }\end{array}$ & $\begin{array}{l}\text { Infection } \\
\text { comorbidities }\end{array}$ & $\begin{array}{l}\text { Infection } \\
\text { comorbidities }\end{array}$ & $\begin{array}{l}\text { Infection } \\
\text { comorbidities }\end{array}$ & $\begin{array}{l}\text { Infection } \\
\text { comorbidities }\end{array}$ & $\begin{array}{l}\text { Infection } \\
\text { comorbidities }\end{array}$ \\
\hline Female & 12278 & 100003.67 & 646 & 5261.44 & 1.00 & 1.00 \\
\hline Male & 6666 & 55516.31 & 446 & 6690.67 & $\begin{array}{l}1.25 \\
\left(1.11^{\sim} 1.41\right)\end{array}$ & $\begin{array}{l}1.26 \\
\left(1.11^{\sim} 1.42\right)\end{array}$ \\
\hline \multicolumn{7}{|l|}{ Age } \\
\hline [?] 16 & 357 & 3095.73 & 5 & 1400.56 & 1.00 & 1.00 \\
\hline$>16$ & 18587 & 152424.25 & 1087 & 5848.17 & $\begin{array}{l}4.37 \\
\left(1.81^{\sim} 10.51\right)\end{array}$ & $\begin{array}{l}4.50 \\
\left(1.87^{\sim} 10.83\right)\end{array}$ \\
\hline \multicolumn{7}{|l|}{$\begin{array}{l}\text { Biologic } \\
\text { agents }\end{array}$} \\
\hline No & 18797 & 154185.62 & 1085 & 5772.20 & 1.00 & 1.00 \\
\hline Yes & 147 & 1334.37 & 7 & 4761.90 & $\begin{array}{l}0.77 \\
\left(0.36^{\sim} 1.61\right)\end{array}$ & $\begin{array}{l}0.81 \\
\left(0.38^{\sim} 1.70\right)\end{array}$ \\
\hline $\begin{array}{l}\text { Miscellaneous } \\
\text { comorbidities } \\
\text { Gender }\end{array}$ & $\begin{array}{l}\text { Miscellaneous } \\
\text { comorbidities }\end{array}$ & $\begin{array}{l}\text { Miscellaneous } \\
\text { comorbidities }\end{array}$ & $\begin{array}{l}\text { Miscellaneous } \\
\text { comorbidities }\end{array}$ & $\begin{array}{l}\text { Miscellaneous } \\
\text { comorbidities }\end{array}$ & $\begin{array}{l}\text { Miscellaneous } \\
\text { comorbidities }\end{array}$ & $\begin{array}{l}\text { Miscellaneous } \\
\text { comorbidities }\end{array}$ \\
\hline Female & 8545 & 53604.52 & 3206 & 5980.84 & 1.00 & 1.00 \\
\hline Male & 4502 & 28281.48 & 1790 & 6329.23 & $\begin{array}{l}1.06 \\
\left(1.01^{\sim} 1.13\right)\end{array}$ & $\begin{array}{l}1.07 \\
\left(1.01^{\sim} 1.13\right)\end{array}$ \\
\hline \multicolumn{7}{|l|}{ Age } \\
\hline [?] 16 & 273 & 2094.36 & 49 & 2339.62 & 1.00 & 1.00 \\
\hline$>16$ & 12774 & 79791.65 & 4947 & 6199.90 & $\begin{array}{l}2.52 \\
\left(1.90^{\sim} 3.34\right)\end{array}$ & $\begin{array}{l}2.55 \\
\left(1.92^{\sim} 3.38\right)\end{array}$ \\
\hline \multicolumn{7}{|l|}{$\begin{array}{l}\text { Biologic } \\
\text { agents }\end{array}$} \\
\hline No & 8601 & 53954.71 & 3220 & 5967.97 & 1.00 & 1.00 \\
\hline Yes & 93 & 826.53 & 7 & 846.92 & $\begin{array}{l}0.15 \\
\left(0.07^{\sim} 0.31\right)\end{array}$ & $\begin{array}{l}0.15 \\
\left(0.07^{\sim} 0.31\right)\end{array}$ \\
\hline
\end{tabular}

- $\quad$ Consent to publish

The authors read and approved the final manuscript and agree to publish. 
- $\quad$ Availability of data and materials

No further underlying research material is associated with this article.

- $\quad$ Competing interests

The author declares no competing interests.

- $\quad$ Funding

MOST: 105-2314-B-182-050-MY3 and MOST 106-2314-B-182A-156-MY3 from the Ministry of Science and Technology of Taiwan and CMRPG8G0272 from Chang Gung Memorial Hospital in Taiwan. Although these institutes provided financial support, they had no influence on the way we collected, analyzed, or interpreted the data or wrote this manuscript.

- $\quad$ Authors' Contributions

YJS participated in draft the manuscript. HCK participated in its design and coordination.

References:

1. Wang, H., et al., Neutrophil Extracellular Trap Mitochondrial DNA and Its Autoantibody in Systemic Lupus Erythematosus and a Proof-of-Concept Trial of Metformin. Arthritis Rheumatol, 2015.67 (12): p. 3190-200.

2. Liu, L., et al., Impact of diabetes mellitus on risk of cardiovascular disease and all-cause mortality: Evidence on health outcomes and antidiabetic treatment in United States adults. World J Diabetes, 2016. 7 (18): p. 449-461.

3. Lin, C.C., et al., Accuracy of diabetes diagnosis in health insurance claims data in Taiwan. J Formos Med Assoc, 2005.104 (3): p. 157-63.

4. Sung, S.F., et al., Validity of a stroke severity index for administrative claims data research: a retrospective cohort study. BMC Health Serv Res, 2016. 16 (1): p. 509.

5. Damjanov, N., M.T. Nurmohamed, and Z. Szekanecz, Biologics, cardiovascular effects and cancer. BMC Med, 2014. 12 : p. 48.

6. Ursini, F., et al., The effect of non-TNF-targeted biologics and small molecules on insulin resistance in inflammatory arthritis.Autoimmun Rev, 2018. 17 (4): p. 399-404.

7. Killinger, Z., et al., Biologic treatment in comparison to methotrexate has positive effect on trabecular bone score in rheumatoid arthritis patients: 1-year follow-up. Acta Clin Belg, 2018: p. 1-5.

8. Zerbini, C.A.F., et al., Biologic therapies and bone loss in rheumatoid arthritis. Osteoporos Int, 2017. 28 (2): p. $429-446$.

9. Maneiro, J.R., A. Souto, and J.J. Gomez-Reino, Risks of malignancies related to tofacitinib and biological drugs in rheumatoid arthritis: Systematic review, meta-analysis, and network meta-analysis.Semin Arthritis Rheum, 2017. 47 (2): p. 149-156.

10. Wilton, K.M. and E.L. Matteson, Malignancy Incidence, Management, and Prevention in Patients with Rheumatoid Arthritis.Rheumatol Ther, 2017. 4 (2): p. 333-347.

11. Ramiro, S., et al., Safety of synthetic and biological DMARDs: a systematic literature review informing the 2016 update of the EULAR recommendations for management of rheumatoid arthritis. Ann Rheum Dis, 2017. 76 (6): p. 1101-1136.

12. Kourbeti, I.S., P.D. Ziakas, and E. Mylonakis, Biologic therapies in rheumatoid arthritis and the risk of opportunistic infections: a meta-analysis. Clin Infect Dis, 2014. 58 (12): p. 1649-57. 
13. Furst, D.E., The risk of infections with biologic therapies for rheumatoid arthritis. Semin Arthritis Rheum, 2010. 39 (5): p. 327-46.

14. Barnabe, C., et al., Sex differences in pain scores and localization in inflammatory arthritis: a systematic review and metaanalysis. J Rheumatol, 2012. 39 (6): p. 1221-30.

15. Kamata, Y. and S. Minota, Wide difference in biologics usage and expenditure for the treatment of patients with rheumatoid arthritis in each prefecture in Japan analyzed using "National Database of Health Insurance Claims and Specific Health Checkups of Japan". Rheumatol Int, 2018. 38 (4): p. 663-668.

16. Stoll, M.L. and A.C. Gotte, Biological therapies for the treatment of juvenile idiopathic arthritis: Lessons from the adult and pediatric experiences. Biologics, 2008. 2 (2): p. 229-52.

17. Borren, N.Z. and A.N. Ananthakrishnan, Safety of Biologic Therapy in Older Patients with ImmuneMediated Diseases: A Systematic Review and Meta-Analysis. Clin Gastroenterol Hepatol, 2019.

18. Singh, J.A., et al., Risk of serious infection in biological treatment of patients with rheumatoid arthritis: a systematic review and meta-analysis. Lancet, 2015. 386 (9990): p. 258-65.

19. Rutherford, A.I., et al., Opportunistic infections in rheumatoid arthritis patients exposed to biologic therapy: results from the British Society for Rheumatology Biologics Register for Rheumatoid Arthritis. Rheumatology (Oxford), 2018. 57 (6): p. 997-1001.

20. Bruce, E.S., et al., Risk of Pneumocystis jirovecii pneumonia in patients with rheumatoid arthritis treated with inhibitors of tumour necrosis factor alpha: results from the British Society for Rheumatology Biologics Register for Rheumatoid Arthritis. Rheumatology (Oxford), 2016. 55 (7): p. 1336-7.

21. Yun, H., et al., Risks of herpes zoster in patients with rheumatoid arthritis according to biologic diseasemodifying therapy.Arthritis Care Res (Hoboken), 2015. 67 (5): p. 731-6.

22. Salliot, C., M. Dougados, and L. Gossec, Risk of serious infections during rituximab, abatacept and anakinra treatments for rheumatoid arthritis: meta-analyses of randomised placebo-controlled trials. Ann Rheum Dis, 2009. 68 (1): p. 25-32.

23. Liao, H., et al., Comparison of the risk of infections in different anti-TNF agents: a meta-analysis. Int J Rheum Dis, 2017.20 (2): p. 161-168.

24. Hussain, M.I., et al., Acute renal failure and metformin-associated lactic acidosis following colonoscopy. Diabetes Res Clin Pract, 2014. 105 (1): p. e6-8.

25. Adam, W.R. and R.C. O'Brien, A justification for less restrictive guidelines on the use of metformin in stable chronic renal failure. Diabet Med, 2014. 31 (9): p. 1032-8.

26. Accortt, N.A., et al., Retrospective analysis to describe associations between tumor necrosis factor alpha inhibitors and COPD-related hospitalizations. Int J Chron Obstruct Pulmon Dis, 2017.12 : p. 2085-2094.

27. de La Forest Divonne, M., J.E. Gottenberg, and C. Salliot,Safety of biologic DMARDs in RA patients in real life: A systematic literature review and meta-analyses of biologic registers.Joint Bone Spine, 2017. 84 (2): p. $133-140$.

28. Hsu, C.S., et al., Risks of hepatocellular carcinoma and cirrhosis-associated complications in patients with rheumatoid arthritis: a 10-year population-based cohort study in Taiwan. Hepatol Int, 2018. 12 (6): p. 531-543.

29. Scott, I.C., S.L. Hider, and D.L. Scott, Thromboembolism with Janus Kinase (JAK) Inhibitors for Rheumatoid Arthritis: How Real is the Risk? Drug Saf, 2018. 41 (7): p. 645-653.

30. Frost, A.E., et al., Giant cell interstitial pneumonitis. Disease recurrence in the transplanted lung. Am Rev Respir Dis, 1993.148 (5): p. 1401-4. 
31. Holdsworth, S., et al., The clinical spectrum of acute glomerulonephritis and lung haemorrhage (Goodpasture's syndrome). Q J Med, 1985. 55 (216): p. 75-86.

32. England, B.R., et al., Chronic lung disease in U.S. Veterans with rheumatoid arthritis and the impact on survival. Clin Rheumatol, 2018. 37 (11): p. 2907-2915.

33. Fernandez-Diaz, C., et al., Abatacept in patients with rheumatoid arthritis and interstitial lung disease: A national multicenter study of 63 patients. Semin Arthritis Rheum, 2018.48 (1): p. 22-27.

34. Druce, K.L., et al., Mortality in patients with interstitial lung disease treated with rituximab or TNFi as a first biologic. RMD Open, 2017. 3 (1): p. e000473.

35. Roubille, C. and B. Haraoui, Interstitial lung diseases induced or exacerbated by DMARDS and biologic agents in rheumatoid arthritis: a systematic literature review. Semin Arthritis Rheum, 2014.43 (5): p. 613-26. 